\title{
Um Novo Sistema para Rastreamento Visual Automático de Cupins
}

\author{
Antonio Fonseca* Yossi Zana \\ Federal University of ABC, 09210-580 Santo André, SP \\ E-mail: ahof1704@gmail.com.br \\ Ives Haifig \\ Paulista State University, 13506-900 Rio Claro, SP \\ E-mail: ihaifig@gmail.com
}

\begin{abstract}
$\underline{\text { RESUMO }}$
Rastreamento simultâneo de muitos objetos é necessário nos casos de investigação do comportamento de organismos vivos, principalmente insetos [1]. Os métodos atuais apresentam dificuldades em registrar com precisão este tipo de comportamento e/ou são de alto custo monetário[2-4].

O objetivo deste trabalho foi o de desenvolver um algoritmo e uma ferramenta computacional capaz de registrar com precisão o movimento simultâneo de dezenas de insetos.

Foi desenvolvido um novo método a partir da combinação de técnicas de estimação de fundo e iluminação, operações de morfologia matemática e rastreamento usando critério de minimização da distância global. No início é estimado o fundo estático por meio da criação de um modelo da iluminação do ambiente com o uso de cálculo da entropia local. O fundo estimado é subtraído do valor de luminância de todos os quadros do vídeo. Após uma limiarização das imagens, é aplicada uma série de operações morfológicas com o objetivo de segmentar somente os insetos, e são registrados os componentes conectados que representam os insetos. A posição de cada elemento é registrada e a cada um determinado intervalo de tempo, a critério do usuário, é calculada a trajetória dos insetos. $\mathrm{O}$ algoritmo de rastreamento escolhe a configuração que minimiza a distância global, ou seja, a soma de todas as trajetórias.

O sistema proposto foi testado em setup de experimentos realizados no campo da biologia comportamental de insetos, especificamente, cupins. Foram utilizados vídeos de cupins em condições experimentais de iluminação infravermelha. O movimento dos cupins registrado pelo sistema e diversos parâmetros foram calculados, entre número total, número de cupins entrando e saindo da arena, velocidade, tempo na arena, distância percorrida e tamanho dos cupins. A Figura 1 apresenta algumas destas medidas: (1a) o número de cupins que entraram ou saíram da arena ao longo do tempo; (1b) a velocidade média dos cupins em a cada trecho de 10 segundos dos vídeos. Em ambas figuras são apresentados resultados para dois vídeos em situações comportamentais diferentes, início e meio do experimento comportamental. Os resultados foram satisfatórios, correspondendo aos valores esperados e apresentando o nível de precisão necessário para a área.

Foi desenvolvida ainda uma intuitiva interface gráfica para usuários a fim de facilitar a operação de usuários não especializados na área em computação, com controle sobre diversos parâmetros da execução (Fig. 2).

Os resultados como um todo sugerem que o novo sistema auxiliará pesquisadores no registro de comportamento animal e resultará em uma grande economia em tempo de registro manual.
\end{abstract}



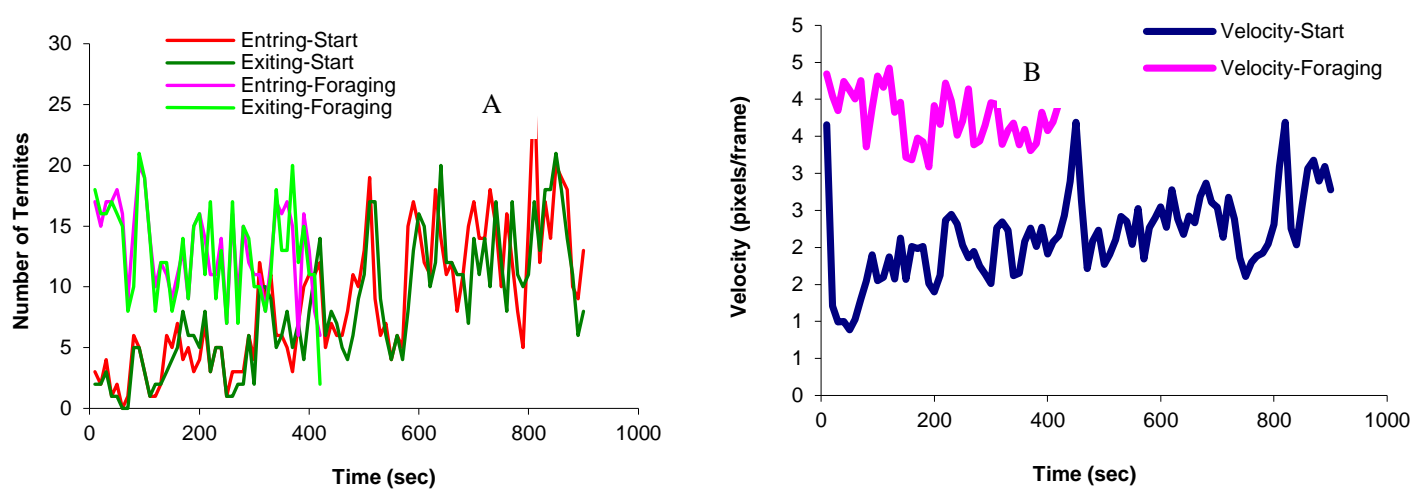

Figura 1. Resultado da análise de vídeos em duas condições experimentais: Início ("start") e meio ("foraging") de um experimento com cupins. Painel A: Número total de cupins entrando ou saindo da arena, ("entring" e "exiting", respectivamente) em segmentos de 10 segundos. Painel B: Velocidade média dos cupins em segmentos de 10 segundos ao longo dos vídeos.

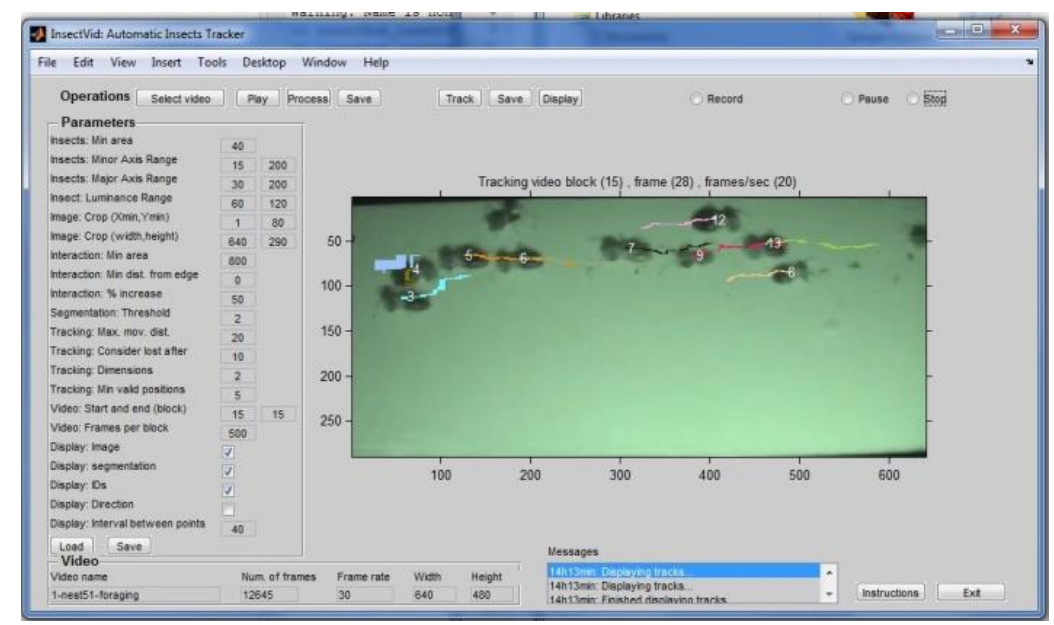

Figura 2. Interface gráfica do Usuário. Na coluna esquerda o usuário pode definir uma série de parâmetros de controle da análise. Em baixo são apresentados propriedades do vídeo. No centro é apresentada a visualização gráfica do vídeo original e do resultado da segmentação e rastreamento.

Palavras-chave: Visão computacional, Insetos, Rastreamento, comportamento animal

\section{Referências}

[1] T. Balch, Z. Khan, M. Veloso, Automatically tracking and analyzing the behavior of social insect colonies, em "Proceedings of the 5th International Conference on Autonomous Agents", pp. 521-528, 2001.

[2] H. Pirsiavash, D. Ramanan, C.C. Fowlkes, Globally-optimal greedy algorithms for tracking a variable number of objects, em "IEEE conference on Computer Vision and Pattern Recognition", pp. 1201-1208, 2011.

[3] B. Benfold, I.D. Reid, Stable multi-target tracking in real-time surveillance video, em "IEEE conference on Computer Vision and Pattern Recognition", pp. 3457-3464, 2011.

[4] M. Fletcher, A. Dornhaus, M.C. Shin, Multiple Ant Tracking with Global Foreground Maximization and Variable Target Proposal Distribution, em "IEEE Workshop on Applications of Computer Vision", pp. 570 - 576, 2011.

[5] C. Poff, H. Nguyen, T. Kang, M.C. Shin, Efficient Tracking of Ants in Long Video with GPU and Interaction, em "IEEE Workshop on Applications of Computer Vision", pp. 57-62, 2012. 